\title{
The complexity of TRIM28 contribution to cancer
}

Patrycja Czerwińska ${ }^{1,2^{*}}$ (D), Sylwia Mazurek ${ }^{1,2,3}$ and Maciej Wiznerowicz ${ }^{1,2}$

\begin{abstract}
Since the first discovery in 1996, the engagement of TRIM28 in distinct aspects of cellular biology has been extensively studied resulting in identification of a complex nature of TRIM28 protein. In this review, we summarize core biological functions of TRIM28 that emerge from TRIM28 multi-domain structure and possessed enzymatic activities. Moreover, we will discuss whether the complexity of TRIM28 engagement in cancer biology makes TRIM28 a possible candidate for targeted anti-cancer therapy. Briefly, we will demonstrate the role of TRIM28 in regulation of target gene transcription, response to DNA damage, downregulation of p53 activity, stimulation of epithelial-to-mesenchymal transition, stemness sustainability, induction of autophagy and regulation of retrotransposition, to provide the answer whether TRIM28 functions as a stimulator or inhibitor of tumorigenesis. To date, number of studies demonstrate significant upregulation of TRIM28 expression in cancer tissues which correlates with worse overall patient survival, suggesting that TRIM28 supports cancer progression. Here, we present distinct aspects of TRIM28 involvement in regulation of cancer cell homeostasis which collectively imply pro-tumorigenic character of TRIM28. Thorough analyses are further needed to verify whether TRIM28 possess the potential to become a new anti-cancer target.
\end{abstract}

Keywords: TRIM28, KAP1, Cancer, Transcriptional co-repressor, EMT, Autophagy, Cancer stem cells

\section{Background}

This work is focused on highly complex TRIM28 protein which role in the biology of normal and cancer cell has been studied for over 20 years [1-3]. First described as a universal co-factor for a huge family of Krüppel-Associated Box Zinc Finger Protein (KRAB-ZFP) transcription factors [2], TRIM28 is now known to participate in many aspects of cellular biology, either promoting cell proliferation [4] or mediating anti-proliferative activities [5]. Trying to answer the question whether TRIM28 acts as a tumor-inhibiting or tumorstimulating factor, we delineate the cancer-related roles of TRIM28. Here we demonstrate the involvement of TRIM28 protein in regulation of gene expression through heterochromatin formation, mediation of DNA damage response, inhibition of p53 activity through intrinsic E3 ubiquitin ligase activity, regulation of epithelial to mesenchymal transition (EMT) and maintenance of stem cell pluripotency as well as regulation of autophagy and safeguarding the genome stability through inhibition of retrotransposition (Fig. 1).

\footnotetext{
* Correspondence: patrycja.czerwinska@wco.pl

${ }^{1}$ Laboratory of Gene Therapy, Department of Diagnostics and Cancer Immunology, Greater Poland Cancer Centre, 15 Garbary Street, 61-866 Poznan, Poland

2Department of Cancer Immunology, Chair of Medical Biotechnology, Poznan University of Medical Sciences, Poznan, Poland

Full list of author information is available at the end of the article
}

\section{Structure and post-translational modifications of TRIM28 protein}

TRIM28 protein, a large multi-domain protein $(110 \mathrm{kDa})$, which is a member of a family of almost 60 human Tripartite motif-containing (TRIM) proteins, is also known as KAP1 (Krüppel-Associated Box (KRAB)-Associated Protein 1 ) or TIF1- $\beta$ (Transcriptional Intermediary Factor $1 \beta$ ) [2, 6]. TRIM28 shares many structural features with three other TRIM proteins, TRIM24 (TIF1 $\alpha$ ), TRIM33 (TIF1 $\gamma$ ), and TRIM66 (TIF1 $\delta$ ), and together constitute a Transcriptional Intermediary Factor 1 (TIF1) family [7, 8]. At the amino $(\mathrm{N})$ terminus, TRIM28 protein contains four conserved structural domains that include a RING (Really Interesting New Gene) finger, two B-boxes, and a leucine zipper coiled-coil region (CC), which are collectively called the RBCC or TRIM domain (Fig. 2) [9, 10]. RING finger domain is a cysteine-rich sequence characterized by the amino acid signature $\mathrm{Cys}_{3}$-His-Cys 4 which binds two zinc cations and together with two B-Boxes and a leucine zipper, is responsible for the interaction with the KRAB domain present in a very large set of the KRAB- Zinc Finger (KRAB-ZFP) transcription factors $[2,9,11]$.

The central part of the TRIM28 protein contains the $\mathrm{P} x \mathrm{~V} x \mathrm{~L}$ pentapeptide region that mediates interaction with Heterochromatin Protein 1 (HP1). In addition, TRIM28 


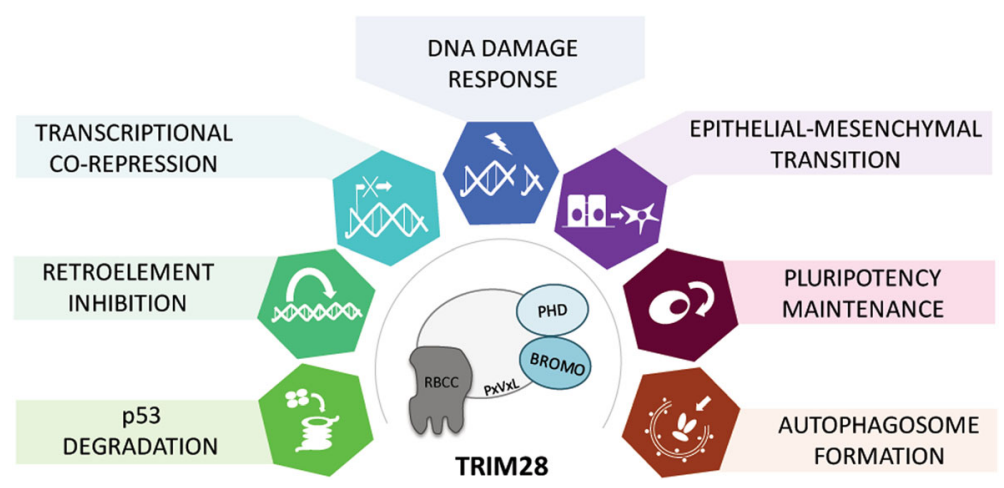

Fig. 1 TRIM28 multi-domain protein contributes to the regulation of a variety of intracellular processes. Core biological functions of TRIM28 including inhibition and degradation of p53 tumor suppressor, regulation of retrotransposition, regulation of gene expression through heterochromatization, mediation of DNA damage response, stimulation of EMT, maintenance of stem cell pluripotency and stimulation of autophagophore formation (induction of autophagy) are frequently intercepted by cancer cells to promote the proliferation and acquire resistance to stress inducing agents

protein also shares with other TIF1 proteins the central TIF1 signature sequence (TSS) consisting of a 25-amino acid tryptophan- and phenylalanine-rich sequence [12].

At the carboxyl (C) terminus of TRIM28, the plant homeodomain (PHD) finger and the Bromodomain are located, recruiting components of the Nucleosome Remodeling Deacetylase (NuRD), histone deacetylase complex and the histone H3 lysine 9 (H3K9)-specific methyltransferase SETDB1 in order to condense chromatin. The PHD finger, as well as the RING domain, is a cysteine/histidine rich structure and contains a consensus $\mathrm{Cys}_{4}$-His-Cys 3 that spans 50-80 residues. The PHD, Bromodomain, and $\mathrm{P} x \mathrm{~V} x \mathrm{~L}$ domain are thought to cooperatively form condensed heterochromatin characterized by the low histone acetylation, high tri-methylation of H3K9 (H3K9me3), and high HP1 binding [13, 14]. This co-repressive activity of TRIM28, including the recruitment of SETDB1 and the NuRD complex and interaction with HP1 protein, is dependent on the SUMOylation state of at least 3 lysine residues (K554, K779, and K804), with TRIM28 itself functioning as an intramolecular E3 SUMO ligase. The PHD domain of TRIM28 protein binds to Ubc9 and directs SUMO conjugation of an adjacent Bromodomain, and this SUMOylation is required for KRAB- TRIM28-mediated gene repression [14].

\section{TRIM28 expression in cancer}

To date, the clinical relevance of TRIM28 in diseases remains elusive. However, several reports revealed positive correlation between the level of TRIM28 expression and cancer prognosis in specific cancer types. TRIM28 is ubiquitously expressed throughout development, with very high expression in embryonic stem cells [15] and several types of tumors (see below). Higher TRIM28 gene expression has been linked to prometastatic cervival cancer [16]. Moreover, the upregulation of TRIM28

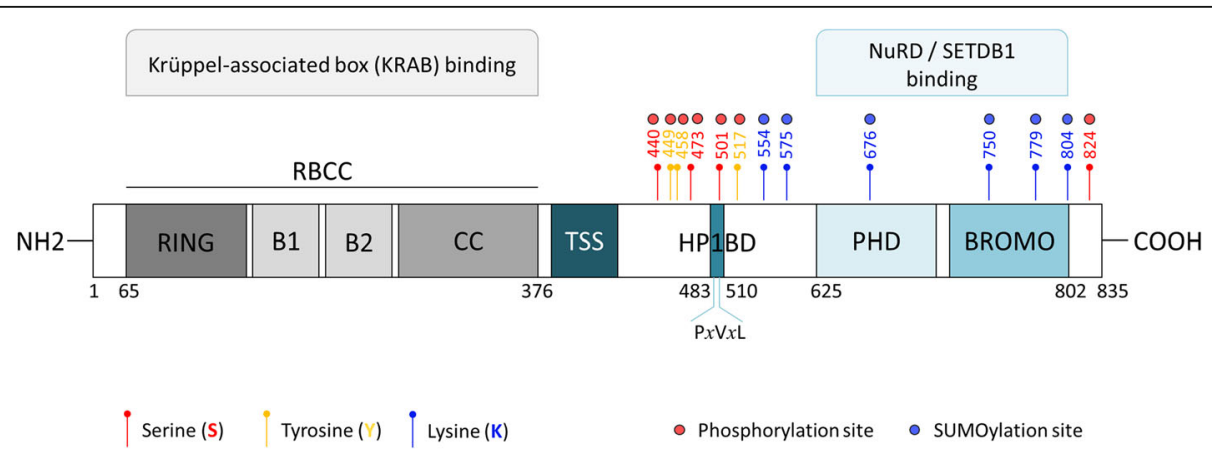

Fig. 2 Structure and post-translational modifications of TRIM28 protein. RING - Really Interesting New Gene; zinc finger type domain which contains a $\mathrm{C}_{3} \mathrm{HC}_{4}$ amino acid motif that binds two zinc cations; has an intrinsic E3 Ubiquitin ligase activity; B1, B2 - B-box type 1 and B-box type zinc finger type domains of around 40 amino acid residues in length; CC - Coiled Coil, a structural motif in which 2 alpha-helices are coiled together (like the strands of a rope); RBCC - RING domain followed by B-boxes and CC domain, RBCC domain is responsible for interaction with KRAB domain of KRAB-ZFPs; TSS - TRIM Specific Sequence; HP1BD - HP1 protein binding domain, contains a consensus PxVxL motif; PHD - Plant Homeodomain, zinc finger type domain which contains a $\mathrm{C}_{4} \mathrm{HC}_{3}$ amino acid motif that binds two zinc cations, has an intrinsic E3 SUMO ligase activity; BROMO - Bromodomain, together with PHD are responsible for NuRD/SETDB1 recruitment and binding 
gene in tumor tissues has been shown in gastric cancer and is associated with poor prognosis [17]; TRIM28 gene overexpression was also detected in peripheral blood of gastric cancer patients [18]. The expression level of TRIM28 was also higher in ovarian cancer samples than in matched non-tumor ovarian tissues and correlated with aggressive clinical features [19]. Furthermore, TRIM28 high expression was an independent predictor for ovarian cancer patients [20]. TRIM28 was also highly expressed in glioma when compared to non-glioma controls and its expression was positively correlated with tumor malignancy, and associated with poor overall survival (OS) and progression-free survival (PFS) [21]. Moreover, recent studies discovered TRIM28 as a possible tumor-class predictive biomarker, used to distinguish glioblastomas from lower grade gliomas, and from reference samples with a unique nanobody-based antiproteome approach [22]. Furthermore, both the mRNA and protein level of TRIM28 were significantly higher in tumor tissues than in adjacent normal tissues in hepatocellular carcinoma patients (HCC). Importantly, the expression of TRIM28 was closely correlated with tumor size, tumor stage and 5-year overall survival in HCC patients, showing remarkably shorter survival rate in patients with TRIM28 overexpression [23]. Consequently, TRIM28 was suggested as an independent prognosis factor to predict the survival rate of HCC patient. Previous studies have shown that TRIM28 was overexpressed in both liver and peritoneal metastases from patients with colorectal adenocarcinoma, melanoma and malignant thyroid tumors [24]. Similarly, analysis of tissue microarrays demonstrated that TRIM28 level is increased during the clinical progression of nearly $40 \%$ of invasive breast carcinomas in situ to metastasis in lymph nodes [4]. Results obtained in our laboratory [25] are in agreement with data published by Addison JB. et al. [4], demonstrating significant upregulation of TRIM28 gene expression in all four intrinsic breast cancer subtypes and in breast cancer metastases when compared to normal tissue. Moreover, TRIM28 level positively correlates with aggressiveness of breast cancers as reported by Wei C. et al. [26]. Immunohistochemical analysis has revealed higher TRIM28 levels in significant proportions of breast, lung, liver, gastric, and prostate tumors (Fig. 3; for more information see TRIM28 at www.proteinatlas.org), suggesting that TRIM28 upregulation is a common feature of many epithelial cancers [16-21, 23-26].

Summing up, aforementioned studies suggest that higher TRIM28 level is linked to a poor prognosis in certain cancers. However, opposite conclusions were also reported. In early-stage lung cancer higher expression of TRIM28 gene is associated with better overall survival [5], suggesting that TRIM28 may have also antiproliferative activity within tumor cells.
Furthermore, liver-specific ablation of $\operatorname{Trim} 28$ in mice increases male-predominant hepatic adenoma, suggesting that TRIM28 protects liver cells from tumorigenic conversion [27]. Indeed, Cassano M. et al. [28] have recently confirmed that Trim28 is a crucial mediator of sexual dimorphism in the liver, tightly regulating the expression of a wide range of bile and steroid metabolism genes. They have demonstrated that hepatocyte-specific Trim28 knockout mice exhibit alterations of transcriptional dynamics exacerbated by environmental insults such as obesity and ageing, consequently leading to male-restricted development of hepatocellular carcinomas [28]. Therefore, TRIM28 is essential for nontumor cells to maintain their unchanged phenotype.

\section{TRIM28 recruitment to the genome and transcriptional co-regulation}

As a transcriptional co-repressor, TRIM28 protein is essential for KRAB-ZNF proteins to unleash their repressive potential. The KRAB-ZNF gene family is specific to tetrapod vertebrates [29] and there are more than 400 human KRAB-ZNF genes encoding transcripts for more than 700 different proteins [30]. This huge family of transcription factors is postulated to regulate diverse processes such as embryonic development, tissue-specific gene expression, and cancer progression [31]. Molecular mechanism of KRAB-ZNF-mediated transcriptional regulation depends on the interaction with chromatin-remodeling factors through the TRIM28 protein (and the formation of transcriptional repressor complex KRAB-ZNF-TRIM28 protein has been mainly studied using artificial assays) [32, 33]. Briefly, KRAB-ZNF proteins bound to specific DNA recognition motifs (transcription factor binding site, TFBS) through their zinc finger domains recruit TRIM28 protein which acts as a scaffold for various heterochromatininducing factors. As mentioned previously, this enrollment is dependent upon the specific interaction of the TRIM28 $\mathrm{N}$-terminal RBCC domain with a conserved KRAB repression domain [9-11]. Next, PHD-mediated SUMOylation of bromodomain and resulting recruitment of SETDB1 and NuRD complex proteins lead to the creation of the H3K9me3 mark on nearby nucleosomes together with deacetylation of histone proteins (Fig. 4) [13, 14]. Further HP1 protein binding to TRIM28 at the $\mathrm{P} x \mathrm{~V} x \mathrm{~L}$ motif and to the H3K9me3 mark, subsequently stabilize the TRIM28containing complex bound to the KRAB-ZNF [34]. It should be noted that neither TRIM28 nor any of the aforementioned proteins recruited by TRIM28 transcriptional co-repressor possess DNA-binding domains. Alterations of chromatin structure due to TRIM28 recruitment to the specific sites of the genome using artificial construct lead to transcriptional repression of RNA polymerase I, II, and III promoters [35-37]. 


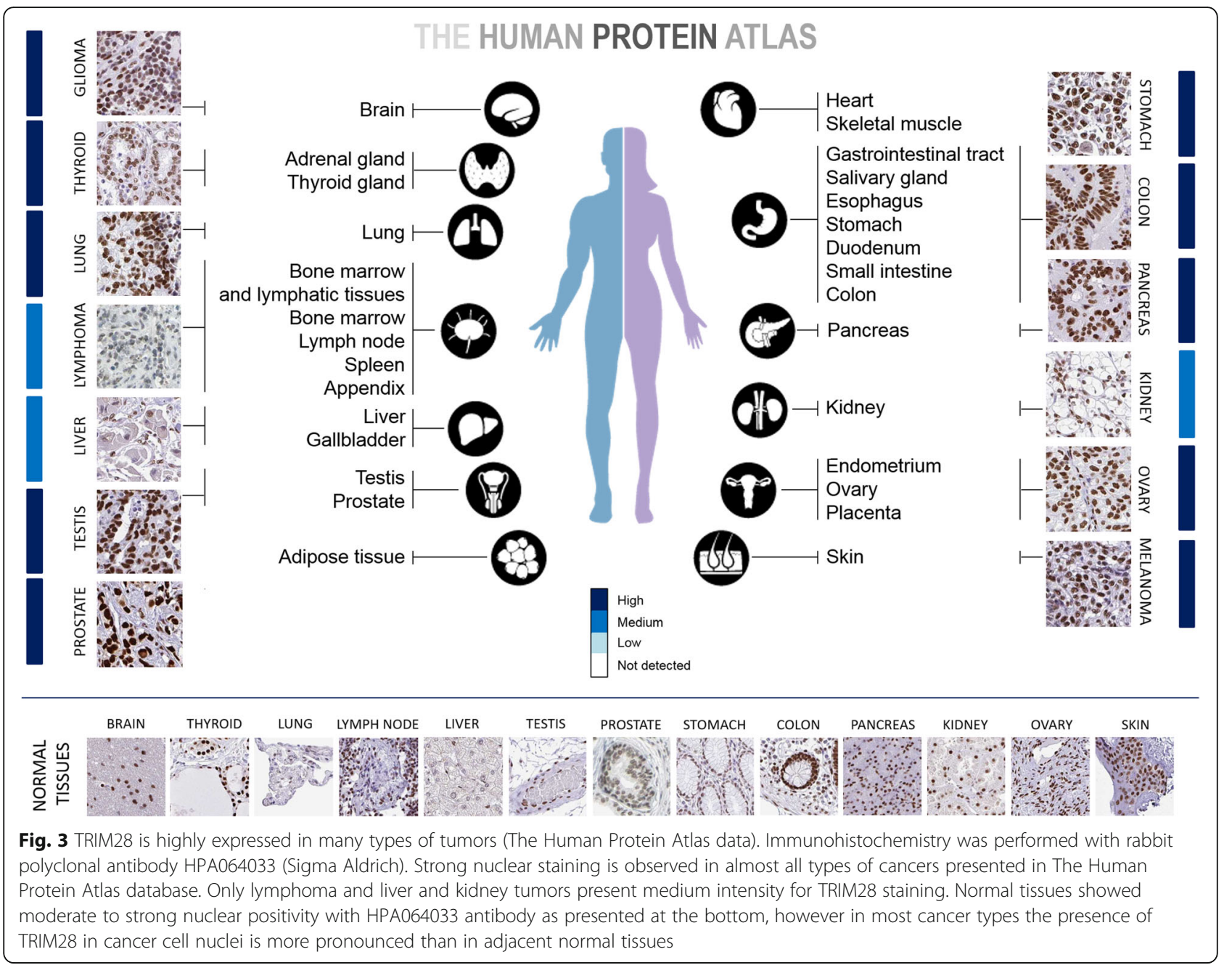

TRIM28 is bound to several different categories of binding sites within the genome, including promoters of nonZNF genes and promoters and 3' exons of ZNF genes. However, Iyengar S. et al. [38] demonstrated that the expression of most genes that are near TRIM28 binding sites was not regulated by TRIM28. Interestingly, the effects of loss of TRIM28 on the human transcriptome were very small, suggesting that the main role of TRIM28 may not lie in transcriptional co-repression through KRAB-ZNF/ TRIM28 mechanism [38]. Moreover, recently published data suggest that TRIM28 recruitment by KRAB domain proteins is not always sufficient to warrant transcriptional repressive activity. Some KRAB-ZNF proteins are poor transcriptional repressors despite their ability to recruit TRIM28, while others show strong KRAB-dependent transcriptional repression, but no TRIM28 binding [39].

Recently, a novel role for the TRIM28 factor in the control of transcriptional elongation was identified [40, 41]. TRIM28 stabilizes the pausing of RNA polymerase II (Pol II) close to the transcriptional start site (TSS) in many unactivated genes [40], permitting Pol II accumulation and readying genes for induction. The modulation of Pol II pausing depends on TRIM28 phosphorylation status. When phosphorylated at Ser824, TRIM28 facilitates Pol II release from the pausing, resulting in rapid transcription of target genes. Moreover, Bunch $\mathrm{H}$. et al. [41] have demonstrated that TRIM28 regulates the transcription of a subset of long non-coding RNAs (lncRNAs) in mammalian cells by similar mechanism of Pol II pausing at their TSS. Mammalian genomes encode a large number of non-coding RNAs that greatly exceed mRNA genes [42, 43], therefore we could speculate the great role of TRIM28 in regulation of genome-wide transcription.

Together, previous reports suggest, that the engagement of TRIM28 in regulation of transcription is very significant however, the complexity of this engagement still remains to be elucidated.

\section{DNA damage response (DDR) pathway and TRIM28 phosphorylation}

The DNA damage response may be elicited in cell by many cytotoxic DNA lesions, such as double-strand breaks 


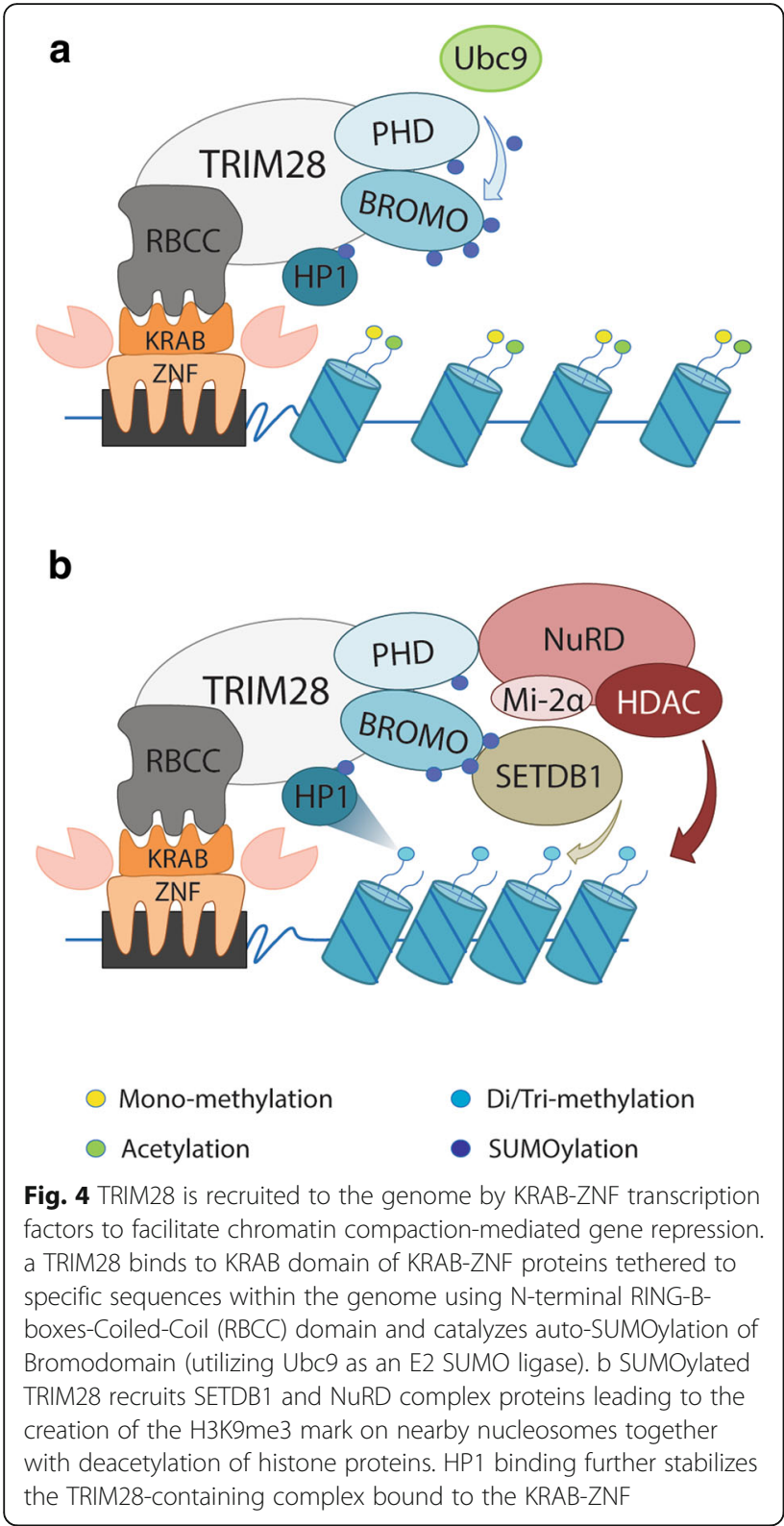

(DSB). This type of damage requires activation of AtaxiaTelangiectasia Mutated (ATM) kinase, a member of nuclear phosphatidylinositol-3 kinase-like (PIKK) family [44, 45]. Together with ATR (ATM and Rad-3 related) and DNAPK (DNA-dependent protein kinase), ATM kinase triggers damage response pathway by phosphorylating several specific substrates, including H2AX histone, topoisomerase II binding protein 1 (TopBP1), p53 binding protein 1 (53BP1), and breast cancer 1 early onset (BRCA1), as well as itself. In the regions where nucleosome flexibility is constrained by heterochromatic factors (TRIM28, HP1, HDACs, etc.), repair proteins are unable to adequately access or manipulate the DSB [46]. Thus, ATM kinase phosphorylates TRIM28 protein on Ser824 within C- terminus and Ser473 near the HP1 binding domain, disrupting the interaction between TRIM28 and chromatin remodeling factors (Fig. 5). Diminished TRIM28 interactions with heterochromatin provide sufficient elasticity to facilitate DNA repair [47-51].

TRIM28 phosphorylation is a very early event of DNA damage response. White D. et al. [51] have shown that within 5 min after irradiation (9 Gy dose) the rapid, vigorous phosphorylation of TRIM28 protein occurred which decreased dramatically within $3 \mathrm{~h}$ after induction of DNA damage. Ser824-phosphorylation of TRIM28 is observed exclusively at the damage sites, from which TRIM28-Ser824-phospho spreads rapidly throughout the chromatin $[48,51,52]$. Ablation of the Ser824 phosphorylation site of TRIM28 leads to loss of chromatin decondensation induced by double-strand breaks within DNA and renders the cells hypersensitive to DSBinducing agents [48]. Knocking down TRIM28, or mimicking a constitutive Ser824 phosphorylation of this protein (TRIM28-S824D mutant), leads to constitutive chromatin relaxation. Results obtained by Ziv Y. et al. [48] suggest that chromatin relaxation is a fundamental pathway in the DNA-damage response and identify its primary mediators. Mechanistic explanation of phosphoTRIM28-mediated heterochromatin relaxation in response to DNA damage-inducing agents was further demonstrated by Goodarzi A. et al. [49].

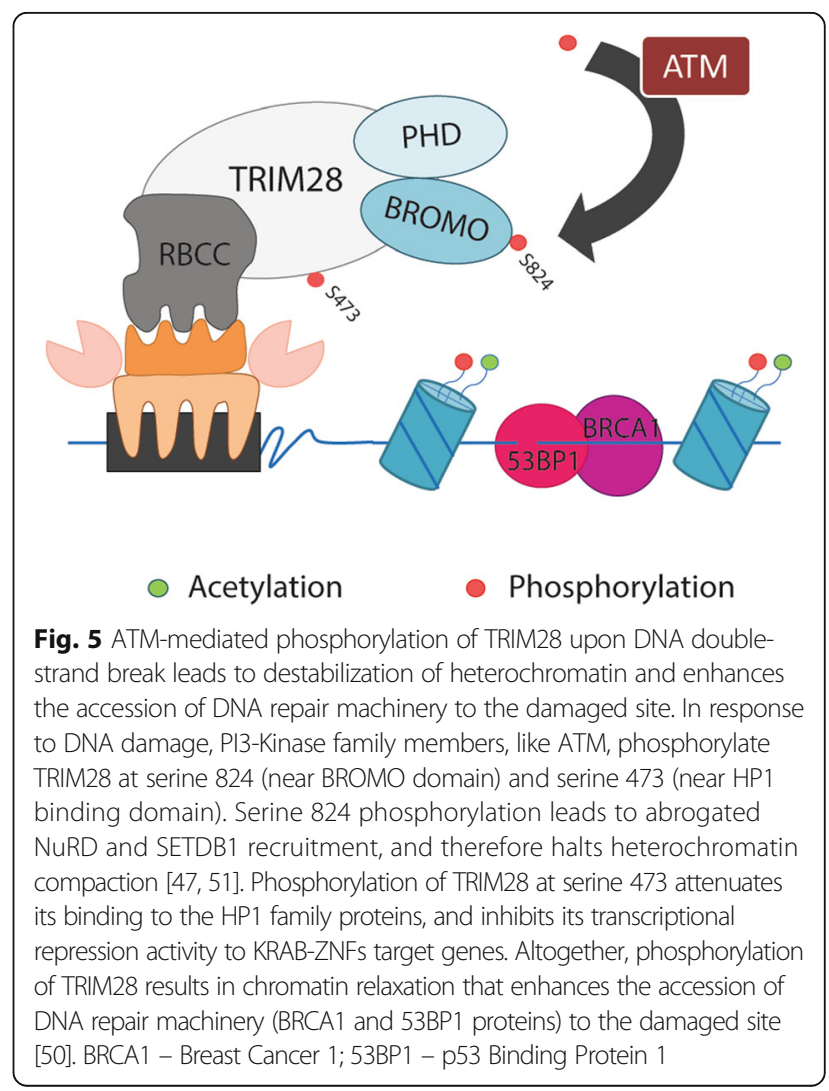


Interestingly, the mechanism of TRIM28-Ser824phosphorylation-dependent regulation of chromatin relaxation was utilized by cancer cells to promote their growth. As presented by Bhatia N. et al. [53], in melanoma cancer cells MAGE-C2 (Melanoma-associated antigen-encoding gene) protein can induce ATMdependent TRIM28-Ser824 phosphorylation favoring DNA damage repair mechanism over apoptosis. MAGEC2 increases co-precipitation of TRIM28 with ATM and binding of MAGE-C2 to TRIM28 is necessary for increased TRIM28-Ser824 phosphorylation, resulting in enhanced DNA damage repair and, consequently, in promoting tumor progression [53].

TRIM28 Ser473 phosphorylation is also involved in efficient DNA repair and cell survival upon DNA damage [51, 54-56]. Depending on the type of DNA damage that occurs, TRIM28 Ser473 is phosphorylated by different DNA damage signaling pathways - Chk2 is the major kinase responsible for TRIM28 Ser473 phosphorylation in the etoposide- or IR-induced stress response, whereas Chk1 is required for TRIM28 Ser473 phosphorylation in response to UV radiation [55, 57-59]. However, unlike the phosphorylation at Ser824, the TRIM28 Ser473 phosphorylation is diffusely localized in the nucleus instead of accumulating at damage sites and forming foci $[48,51,58]$. Moreover, TRIM28 Ser473 phosphorylation proceeds in a slower kinetic manner compared with TRIM28 Ser824 phoshporylation. In their work, $\mathrm{Hu} \mathrm{C}$. et al. [57] have reported that DNA damage-induced TRIM28 Ser473 phosphorylation attenuates its binding to HP1 family proteins, which may lead to an increased binding of TRIM28E2F1 and reduce the ability of E2F1 to activate the expression of a subset of proapoptotic genes and apoptosis. Therefore, TRIM28 contributes to the negative regulation of E2F1 and may serve as a partial backup to prevent E2F1-mediated apoptosis in cancer cells [57, 60], suggesting that TRIM28 acts as a pro-tumorigenic factor.

\section{Regulation of epithelial-to-Mesenchymal transition (EMT)}

The Epithelial to Mesenchymal Transition (EMT) is defined by the loss of epithelial characteristics, mainly cell polarity and cell-cell contacts, and the acquisition of a mesenchymal phenotype [61-63]. EMT may be triggered by multiple extracellular stimuli and transcriptional regulators, but how such distinct signaling pathways orchestrate the complex cellular events that facilitate EMT is not well understood yet [63-65]. EMT was initially recognized during several critical stages of embryonic development and has been implicated in promoting carcinoma invasion and metastasis $[63,64,66]$. Hallmarks of EMT include: (i) the decreased expression of cell adhesion molecules such as E-CADHERIN [63]; (ii) the upregulation of MMPs to assist in the degradation of the basement membrane [67]; (iii) the activation of the Rho/Cdc42 family small GTPase which are necessary to cytoskeleton rearrangement [68]; and (iv) the nuclear translocation of several transcription factors such as $\beta$-CATENIN, TCF/LEF1 ( $T$ Cell Factor/ Lymphocyte Enhancer Factor 1) complex, SNAI1, SNAI2 (also known as SLUG), SIP-1 and TWIST1 [69].

Additionally, the expression of some of these EMT inductors has been detected in a variety of human cancer biopsies, including breast carcinomas [70], and their overexpression is usually related to increased tumor aggressiveness or recurrence, unfavorable clinicopathologic variables, and poor prognosis $[62,64,66]$. Recently, a novel master regulator of EMT was described - a protein-DNA complex composed of TRIM28 protein, CBF-A (CArG box-Binding Factor-A) and the FTS-1 element (Fibroblast Transcription Site-1), the crucial element for the expression of FSP1 (calcium-binding Fibroblast-Specific Protein 1) in fibroblasts (Fig. 6) [71]. FTS-1 sites are present in the promoter regions of multiple genes involved in the EMT process [72], and the CBF-A and TRIM28 proteins recognize and bind to the FTS- 1 sites in the genomic DNA controlling the expression of a wide spectrum of EMT responsive genes. Occupancy of the FTS-1 site by these proteins in the chromatin of epithelia transitioning to fibroblasts correlates with the activation of the EMT proteome [71].

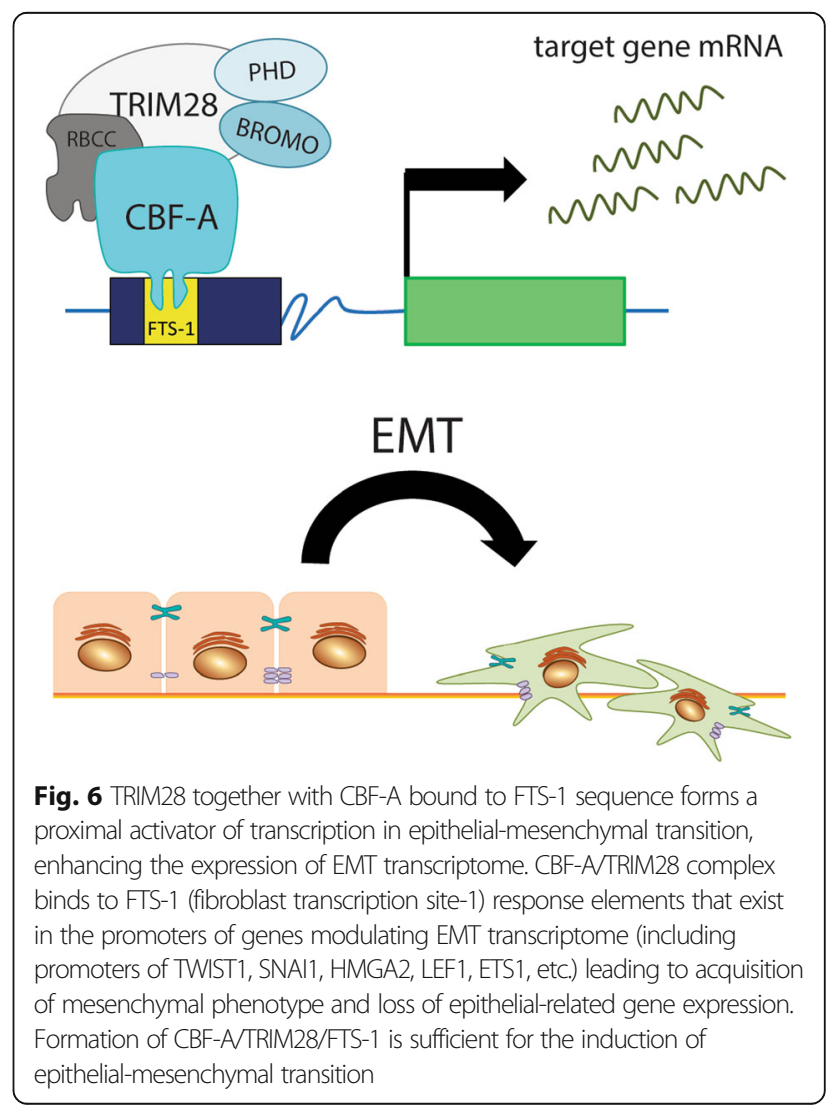


Recently, Lin LF. et al. [16] demonstrated that TRIM28 can promote the invasion of cancer cells and that the acquisition of metastatic properties tends to be associated with EMT regulation. Similarly, Yu C. et al. [73] have observed that TRIM28 overexpression induced the EMT in pancreatic cancer cells both in vitro and in vivo, as indicated by increased expression of mesenchymal markers such as vimentin and decreased expression of E-CADHERIN, suggesting TRIM28 role in promoting metastasis. Furthermore, Chen L. et al. [74] demonstrated that TRIM28 plays a role in TGF- $\beta$-induced EMT in non-small cell lung cancer cells. TRIM28 expression is induced following TGF- $\beta$ treatment, leading to enhanced cell migration and invasion in vitro. This effect is impaired with TRIM28-specific siRNAs. Moreover, TRIM28 has been demonstrated to regulate EMT gene expression (CDH1 encoding E-CADHERIN and $\mathrm{CDH} 2$ encoding N-CADHERIN) through modification of histones of target gene promoters, further implying its role in acquisition of highly aggressive mesenchymal phenotype of cancer cells [74]. Recently, Wei C. et al. [26] have reported that TRIM28 promotes breast cancer metastasis by stabilizing TWIST1 protein - transcription factor considered to be a master regulator of EMT. Overexpression and depletion of TRIM28 led to upregulation and downregulation of TWIST1 protein, but not the mRNA levels of TWIST1, respectively. Knockdown of TRIM28 resulted in TWIST1 downregulation with concurrent upregulation of E-CADHERIN and downregulation of N-CADHERIN that consequently inhibited breast cancer cell migration and invasion in vitro [26]. Therefore, TRIM28 regulates specific mediators of EMT at both transcriptional and posttranscriptional levels.

Importantly, EMT is relevant to the acquisition and maintenance of stem cell-like characteristics and is sufficient to endow differentiated normal and cancer cells with stem cell properties [75, 76]. Moreover, CSCs often exhibit EMT properties. This reciprocal relationship between EMT and CSCs might have many implications in tumor progression and previously demonstrated involvement of TRIM28 protein in regulation of EMT implies its role in cancer stem cell maintenance.

Therefore, TRIM28 is the first potential epigenetic regulator that promotes cell metastasis and may serve as a therapeutic target against cancer in combination with other traditional strategies [16, 77].

\section{Inhibition of p53 activity}

The $\mathrm{p} 53$ protein plays a central role in tumor suppression maintaining genome stability and protecting cells against malignant transformation [78, 79]. In approximately half of the cancers, the TP53 gene is deleted or harbors inactivating mutations. In remaining tumors that retain wildtype TP53, this gene is often inactivated via other genetic or epigenetic alterations [80]. The p53 is regulated by multiple signaling pathways and mechanisms, however, its activity is suppressed mainly by its major regulator MDM2 protein [81-83]. MDM2 binds p53 and functions as an ubiquitin E3 ligase to promote p53 ubiquitination and degradation in the proteasomes [81-83]. MDM2 interacts with a variety of regulatory factors [84]. Among others, TRIM28 was identified as a MDM2-binding protein promoting p53 destabilization [77, 85].

TRIM28 interacts through its coiled-coil (CC) domain with the central acidic domain of MDM2 and this interaction may recruit TRIM28 C-terminal-associated cofactors, such as histone deacetylases. Together with MDM2, TRIM28 protein stimulates the formation of p53-HDAC1 complex and inhibits p53 acetylation. Because acetylation and ubiquitination of p53 use common lysine residues and are mutually exclusive events, the ability of MDM2 to recruit TRIM28 would cooperatively deacetylate and then ubiquitinate p53. Indeed, as shown by Wang C. et al. [85] the RING domain of TRIM28 protein possesses the activity of E3 ubiquitin ligase and enhances p53 ubiquitination level in an MDM2-dependent fashion (Fig. 7). Cells with reduced endogenous TRIM28 level are highly sensitive to p53 activation and apoptosis after DNA damage. Moreover, TRIM28 reduction markedly enhanced the induction of $\mathrm{p} 21^{\mathrm{Cip} 1 / \mathrm{Waf} 1}$, a product of the p53 target gene, after treatment with actinomycin $\mathrm{D}$ or $\gamma$-irradiation resulting in reduced entry of cells in $S$ phase of cell cycle [77, 85].

Therefore, TRIM28 as a novel MDM2-binding protein contributes to p53 functional regulation leading to inhibition of p53 acetylation and subsequent proteasomal degradation $[77,85]$.

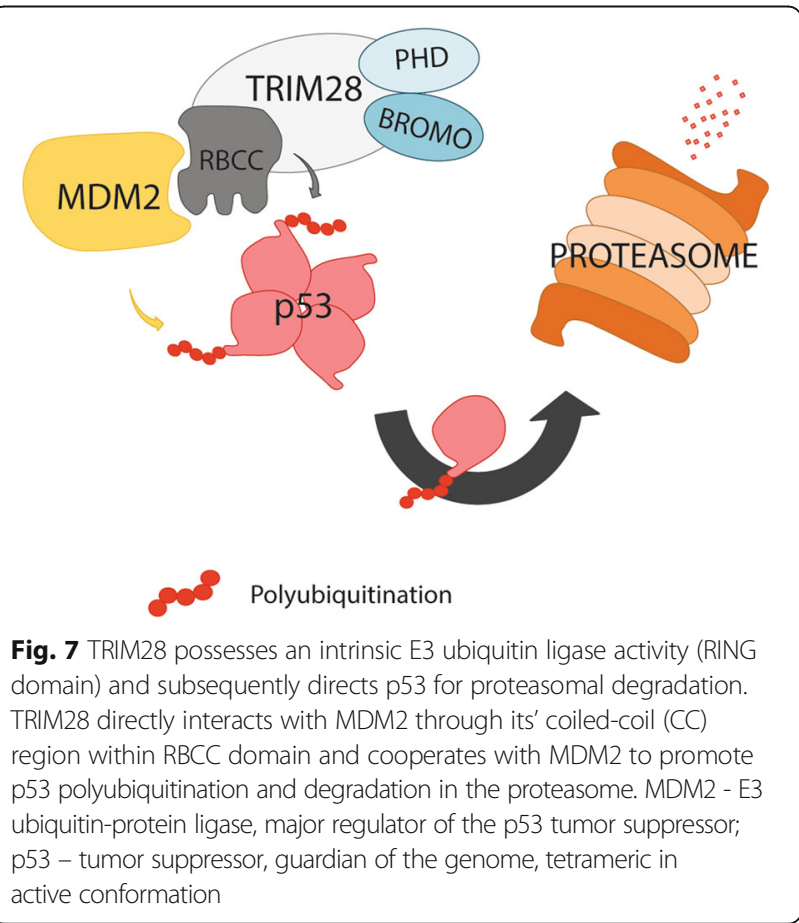


Moreover, the formation of TRIM28-MDM2-p53 complex is enhanced by class I MAGE proteins (MAGE-A, MAGE-B and MAGE-C protein families), which are highly expressed in various cancers [79]. MAGE proteins together with TRIM28 actively promote tumor survival by facilitating MDM2-mediated suppression of p53 activity. However, further studies by Doyle JM. et al. [86] demonstrated that TRIM28 may ubiquitinate p53 independently from MDM2 protein. MAGE proteins enhance the ubiquitin ligase activity of RING domain proteins, such as TRIM28 protein, targeting p53 for degradation in a proteasome-dependent manner independently from MDM2 ubiquitin ligase. These results are consistent with TRIM28 tumorigenic functions.

\section{Maintenance of stem-cell characteristics}

Embryonic stem cells (ESCs) have been used extensively as a model system to study early mammalian development and the molecular control of self-renewal and pluripotency [87, 88]. For the first time, the role of Trim 28 protein in embryonal development in mice was determined in 2000 by Cammas F. et al. [15]. Homozygous Trim $28^{-/-}$(null mutant) embryos, which developed normally until the blastocyst stage and underwent uterine implantation, were arrested in their development at about embryonic day (E) 5.5 (early egg-cylinder stage) and failed to gastrulate, indicating that Trim 28 is essential for early postimplantation mouse development [15]. As presented below, TRIM28 is essential for keeping cells in their intrinsic "state of cell differentiation", facilitating both stem cell maintenance and inhibiting reprogramming of somatic cells.

In 2009 Hu G. et al. [89] have presented the genome-scale functional genetic screen in mouse ESCs for pluripotency genes, which detected Trim 28 as a protein involved in regulation of the expression of pluripotency markers, such as Oct-4 (Octamer-binding Transcription Factor 4), Sox2 ((Sex determining region Y)-Box 2) and Nanog. In their work, $\mathrm{Hu}$ G. et al. [89] discovered that Trim28 depletion resulted in significant down-regulation of Oct-4, Sox 2 and Nanog mRNA expression level and have led to differentiation of ESCs into the primitive ectoderm lineage. Together with other pluripotency markers, Cnot3, Zfx and c-Myc, TRIM28 co-occupies many putative gene promoters and forms a unique module in the self-renewal transcription network that is distinct from the module of Nanog-Sox2-Oct-4. Intriguingly, target genes of all four factors (Cnot3, Trim28, c-Myc, and Zfx) are enriched for cancer genes (as determined by Ingenuity Pathway Analysis) supporting the idea that regulatory networks controlling self-renewal in stem cells may also be active in certain cancers [89].

Furthermore, Seki Y. et al. [90] have demonstrated that phosphorylated at Ser824 Trim28 protein formed a complex with the pluripotency-specific transcriptional factor
Oct- 4 on the promoters of pluripotency-specific genes, and promotes not only the gene expression of pluripotencyspecific transcriptional factors such as Nanog, Sox2, and Oct-4, but also the expression of various chromatin remodeling proteins for efficient control of pluripotent ES cell in a phosphorylation-dependent manner. Also, Jin VX. et al. [91] using ChIP-ChIP analysis combined with a unique bioinformatics approach demonstrated that half of the promoters bound by OCT- 4 and SOX2 were co-occupied by TRIM28 in embryonic carcinoma cells. Moreover, Trim28 protein was recently demonstrated to be SUMOylated in mouse embryonic stem cells by Sumo2 in order to establish provirus silencing through the canonical Zfp809/Trim28/ Eset machinery [92] which ultimately safeguards ESC genome integrity. Also, Cheng B. et al. [93] reported that in contrast to inducing the expression of pluripotency markers, Trim 28 has opposite effects on differentiationinducible markers in mouse ESC. Together with Polycomb repressor 1 (Prc1) complex, Trim28 is bound at the promoters of differentiation-inducible genes repressing the transcription, which further supports the requirement for Trim28 in the maintenance of mESC pluripotency.

Trim28 was also identified as an epigenetic barrier to induced pluripotent stem cell reprogramming [94, 95]. Knockdown of Trim28 during reprogramming of mouse embryonic fibroblasts resulted in increased expression of genes located in repressive chromatin regions (marked with H3K9me3 modifications) and upregulation of specific endogenous retroviruses, indicating a de-condensed and active chromatin state that facilitates the transition through reprogramming [94]. Therefore, Miles DC. et al. suggested that Trim 28 safeguards the differentiated state of somatic cells by maintaining the repression of these regions. Interestingly, Klimczak M. et al. [95] reported that even if depletion of Trim 28 increases the relaxation of chromatin and in consequence facilitates the reset of differentiated state, emerging iPS cells with downregulated Trim 28 expression quickly lose their self-renewal potential and spontaneously differentiate demonstrating that Trim 28 is indispensable for the maintenance of stable iPS cells.

Recently, the indispensable role of TRIM28 for maintaining breast cancer stem cell population has been reported $[25,96]$. Cancer stem cells (CSCs) are rare, tumorinitiating cells that exhibit stem cell properties: capacity of self-renewal, pluripotency, highly tumorigenic potential, and resistance to therapy [97]. In our studies, we have demonstrated that downregulation of TRIM28 in highly aggressive, undifferentiated cells of triple-negative breast cancer MDA-MB-231 cell line, which is highly enriched in vitro in CSC-like population characterized by CD44 ${ }^{+} \mathrm{CD} 24^{-/ \text {low }}$ phenotype, led to significant $(p<0.0001)$ inhibition of tumor growth in vivo upon subcutaneous cell injection into athymic nude mice [25]. Global analysis of gene expression (RNA Seq and in silico analyses) of 
MDA-MB-231 wild-type and TRIM28-downregulated xenografts revealed substantial reduction of pluripotency markers expression as well as significant inhibition of signaling pathways previously reported to control the complex mechanism of stem cell maintenance. Moreover, the loss of CSC population in TRIM28-depleted MDA-MB231 xenografts was further validated with limiting dilution assay (LDA) in vivo. Also, Li J. et al. [96] have observed that TRIM28 together with EZH2, a member of Polycomb Repressor 2 (PRC2) Complex, co-regulates a set of genes associated with stem cell maintenance and poor survival of breast cancer patients. TRIM28 depletion in MCF7 breast cancer cell line in vitro resulted in significant inhibition of $\mathrm{CD} 44^{+} \mathrm{CD} 24^{-/ \text {low }}$ mammosphere formation, which correlated with decreased expression of stem-cell associated genes. These results demonstrate substantial role for TRIM28 in activation of gene expression that promotes mammary stem cell enrichment and maintenance and further underlines TRIM28 engagement in promoting cancer progression [96].

Altogether, TRIM28 maintains both normal and cancer stem cells in the pluripotent state at least partially by repressing the genes associated with differentiation and inducing expression of stemness markers [25, 89, 90, 93, 96]. On the other hand, TRIM28 is an epigenetic barrier to induced reprogramming and downregulation of TRIM28 level facilitates rapid acquisition of stem-like phenotype upon exogenous expression of Yamanaka's reprogramming factors $[95,96]$. This collectively suggests that TRIM28 safeguards the intrinsic "state of cell differentiation", maintaining stem cells and somatic cells in the pluripotent and differentiated state, respectively, and suggests that modulation of TRIM28 level may contribute to destabilization of cell differentiation state.

\section{Induction of autophagosome formation and role in the regulation of cancer cell metabolism}

Cancer cells utilize various strategies like high glycolytic flux, redox signaling, and modulation of autophagy to avoid cell death and overcome nutritional deficiency. Autophagy allows the cancer cell to recycle intracellular proteins and organelles in lysosomes to provide an alternative source of energy during periods of metabolic stress [98, 99]. Recent reports demonstrated that autophagy is mechanistically linked to the maintenance of cancer stem cells [100-102] and enables these cells to overcome drug toxicity [103]. Interestingly, TRIM28 protein is involved in regulation of autophagy at several distinct levels [104-106].

Significant role for TRIM28 protein in coordination of phagophore formation was reported by Yang Y. et al. [104]. The induction and nucleation of the phagophore depends on the activity of the adenosine monophosphate (AMP)-activated protein kinase (AMPK) and mammalian
Target Of Rapamycin Complex 1 (mTORC1)-regulated serine threonine kinase Unc-51-Like Kinase 1/2 (ULK1/ 2) complex $[99,107]$. However, the phagophore formation also critically depends on the production and availability of phosphatidylinositol 3-phosphate [PI(3)P] which is controlled by the activity of VPS34 protein - Vacuolar Sorting Protein 34, the class III Phosphatidyl Inositol-3-OH Kinase (PI3K), also known as PI3K catalytic subunit type 3 (PI3KC3). VPS34 recruits the other autophagy regulatory proteins involved in phagophore and autophagic vesicle (AV) formation [107, 108]. Together with its binding partner - BECLIN1, VPS34 forms a complex, which is further bound by TRIM28 protein (Fig. 8). As a SUMO E3 ligase (through PHD domain), TRIM28 protein mediates Lys840 SUMOylation of VPS34, increasing its activity and enhancing autophagosome formation. TRIM28 protein is recruited to VPS34-BECLIN1 complex by acetylated HSP70 protein in response to stress stimuli, including stress caused by exposure to anticancer agents such as etoposide or doxorubicin, or exposure to heat shock, UV light, or reactive oxygen species (ROS), which are well known to induce autophagy [104]. Moreover, TRIM28 is also involved in regulation of mitophagy - a selective degradation of mitochondria by autophagy [109]. Together with KRAB-ZNF proteins, TRIM28 repress the expression of specific microRNA that target mitophagy-associated genes and therefore, sustain the proper mechanism of mitophagy during the erythropoiesis. However, it is not known whether similar mechanism is utilized by cancer cells.

On the other hand, TRIM28 protein was demonstrated in a complex with MAGE-A protein, forming MAGE-ATRIM28 ubiquitin E3 ligase that targets a master cellular energy sensor and regulator AMPK kinase for ubiquitination and degradation, resulting in decreased AMPK

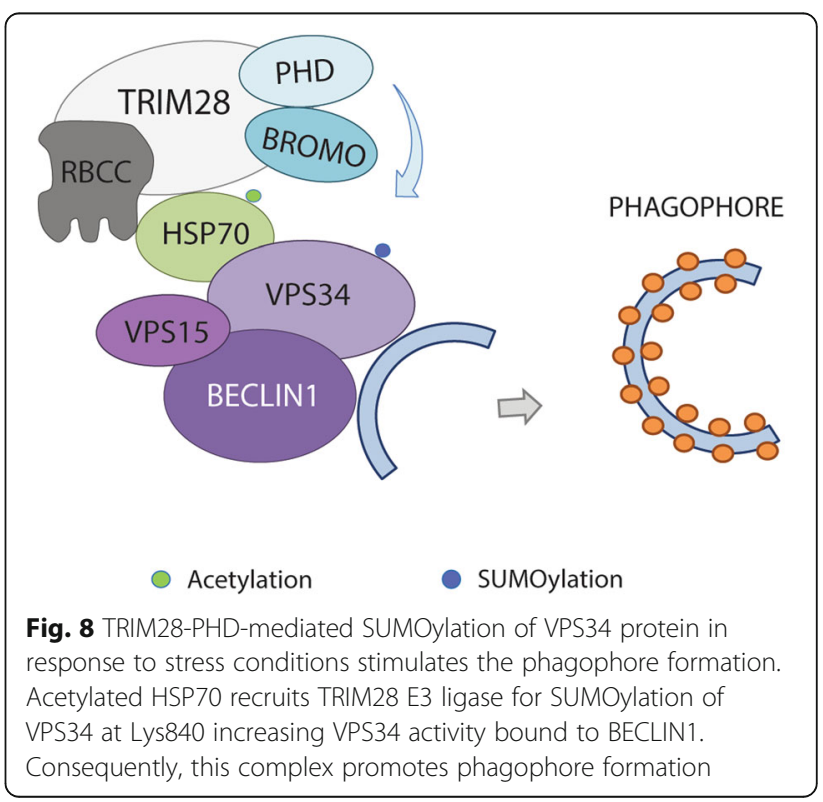


signaling, amplification of mTORC signaling, and downregulation of autophagy $[105,106]$. The authors suggest that expression of MAGE-A3/6 in cancer cells has the ability to act as a molecular switch to convert TRIM28 from a pro-autophagy (induction of phagophore formation) to an anti-autophagy factor by targeting AMPK for degradation $[105,106]$.

Moreover, formation of MAGE-TRIM28 ubiquitin ligase complexes was also demonstrated to promote the Warburg effect and hepatocellular carcinoma progression by targeting Fructose-1,6-biphosphatase (FBP1), a rate-limiting enzyme in gluconeogenesis, for degradation [110]. High expression of TRIM28 increased glucose consumption and lactate production by promoting FBP1 degradation in hepatocellular carcinoma and resulted in stimulation of cancer cells growth both in vitro and in mice model. These results strongly evidence TRIM28 pro-tumorigenic activity.

Clearly, TRIM28 involvement in the regulation of cancer cell metabolic state is complicated and requires further analyses.

\section{Repression of transposable elements}

Genetic instability is one of the key features associated with development and progression of cancer. Among other factors contributing to this instability, transposable elements (TE) have been reported to cause several types of cancer through insertional mutagenesis of specific genes critical for suppressing or driving malignant transformation [111]. Although a large proportion (about $44 \%$ ) of the human genome is occupied by transposons and transposon-like repetitive elements, only a small proportion (less than $0.05 \%$ ) of these elements remain active today $[112,113]$. Human TEs include members of both DNA and RNA families of transposons. The activity of RNA transposons, also termed retroelements, is controlled in embryonic stem cells by a rigorously orchestrated epigenetic process, engaging KRAB-ZNF repressors together with their cofactor Trim28 [114-116].

Ten years ago, Wolf D. and Goff SP. [117] have identified TRIM28 as a component of the repressor binding site (RBS)-binding complex, mediating epigenetic silencing of retroviruses in embryonic stem cells and embryonic carcinoma cells. Later, Rowe HM. et al. [114] have shown that Trim 28 depletion resulted in upregulation of a range of retroelements, in particular intracisternal Atype particles (IAP), in mouse embryonic stem cells and in early embryos. Trim 28 downregulation led to the loss of histone 3 lysine 9 trimethylation (H3K9me3) repressive chromatin mark localized at the $5^{\prime}$ untranslated region (5'UTR) of IAP genomes and therefore, to overexpression of IAPs [114]. Moreover, in Trim28-depleted mouse embryonic stem cells, repressive chromatin marks positioned at retroelements are replaced by histone modifications typical of active enhancers, stimulating transcription of nearby cellular genes, notably those harboring bivalent promoters [115]. Trim28mediated control of retroelement expression is therefore crucial to safeguard the transcriptional dynamics of early embryos. In contrast, loss of Trim28 in mouse embryonic fibroblast (MEF) cells did not lead to an upregulation of retrotransposon expression, indicating a minor role for retrotransposon silencing in differentiated cells $[114,115,118]$. However, it was recently reported by Van Meter M. et al. [119] that Trim28 enforces the silencing of L1 (LINE 1 retroelement) in mouse fibroblasts by coordinating the packaging of these transposable elements into transcriptionally repressive heterochromatin upon mono-ADP ribosylation by SIRT6 protein. This modification is critical for the recruitment of HP1 $\alpha$ and additional silencing factors at the target locus. However, they do not explain how Trim 28 is recruited to specific site of the chromatin where the retroelement L1 is positioned. Castro-Diaz N. et al. [120] identified a novel KRAB-ZFP responsible for tethering Trim 28 to and controlling the expression of a subset of L1 retroelements in mouse embryonic stem cells, strongly suggesting that these DNA-binding proteins are collectively involved in recognizing this class of retroelements [121]. Analogous results were further obtained in human embryonic stem cells [122].

However, it is still questionable whether similar mechanisms may be governed by cancer cells. In contrast to normal cells, the majority of human cancers, and cancer-derived cell lines, support variable, but typically much higher endogenous full-length L1 mRNA expression $[111,123,124]$ despite frequent TRIM28 upregulation. Recently, Mita P. et al. [125] have reported significant role in regulation of L1 expression mediated by novel URI-PP2A-TRIM28 complex in prostate cancer cells. URI (Unconventional prefoldin RPB5 Interactor), a transcriptional repressor that interacts with RNA polymerase II [126], was shown to bind and induce dephosphorylation of DNA-tethered TRIM28-Ser824 by recruitment of PP2A phosphatase, resulting in transcriptional repression of L1 retroelement. In their work, Mita P. et al. [125] have observed significant upregulation of L1 mRNA level upon TRIM28-Ser824 phosphorylation (and chromatin decondensation), which was elicited by depletion of URI and consequent inhibition of PP2A recruitment to TRIM28 phospho-Ser824. Therefore, retroelements usually kept dormant in heterochromatic regions are tightly controlled by TRIM28 phosphorylation status. It is worth to consider whether DNA damage inducing agents triggering misregulation of DNA structure through altered phosphorylation of TRIM28 may consequently result in aberrant regulation of retroelements in cancer cells. 


\section{Conclusion}

Role of TRIM28 in cancer cells has been questioned for more than 15 years. The multitude and complexity of TRIM28 actions in cancer make it difficult to unambiguously establish whether TRIM28 is a cancer promoting agent or possess anti-proliferative activity. Therefore, cancer-associated proteins that were previously reported to interact with TRIM28 or be post-translationally regulated by TRIM28 are summarized in Table 1 . Number of reports suggest that TRIM28 may serve as a protumorigenic factor that when highly expressed, may facilitate cancer progression and metastasis by inducing EMT [71, 73, 74], mediating metabolic switch in stressed conditions [104-106] and downregulating the activity of p53 [77, 85, 127], which collectively enable cancer cells to progress through the cell cycle despite number of errors within the genome. In unstressed cancer cells TRIM28 represses the expression of pro-apoptotic genes: TP53AIP1, BAX, BBC3 (PUMA) and PMAIP1 (NOXA), further suggesting that TRIM28 provides survival advantage to cancer cells $[128,129]$.

However, there are thousands of TRIM28 binding sites within the genome but only few cellular genes that respond to loss of TRIM28 [38], which might suggest that a major role of TRIM28 is to generally guard genome integrity. Therefore, TRIM28 prevents genome destabilization and parallelly, blocks the path of cancer development. Also, tight regulation of retroelement repression suggests that TRIM28 acts as an anti-tumorigenic factor, safeguarding normal cell from cancer transformation in a phosphorylation-dependent manner [125]. However, phosphorylation of specific TRIM28 residues is also connected with DNA damage response pathway and TRIM28-Ser824-phosphorylation-dependent regulation of chromatin relaxation is utilized by melanoma cancer cells to promote their growth [53]. Furthermore, TRIM28 is an indispensable regulator of stem cell pluripotency, facilitating self-renewal of both normal and cancer stem cells [25, 90] and TRIM28-dependant maintenance of CSC population certainly represents pro-tumorigenic function of TRIM28.

Therefore, the mode of TRIM28 action is highly context-dependent, with many reports strongly implying its' cancer promoting features. Undoubtedly, further studies are necessary to define the exact role of multidomain TRIM28 protein in cancer development and progression. Also, better understanding of TRIM28 involvement in carcinogenesis may help to answer whether TRIM28 possess the potential to become a new anti-cancer target.

Table 1 The cancer-associated TRIM28 targets or interacting proteins

\begin{tabular}{|c|c|c|c|c|c|}
\hline $\begin{array}{l}\text { Target or } \\
\text { interacting } \\
\text { protein }\end{array}$ & Modification & Effect & Outcome & $\begin{array}{l}\text { Oncogenic or } \\
\text { tumor suppressive }\end{array}$ & Ref. \\
\hline p53 & $\begin{array}{l}\text { deacetylation/ } \\
\text { poly-ubiquitination }\end{array}$ & inactivation/degradation of p53 & $\begin{array}{l}\text { suppression of p53-mediated } \\
\text { apoptosis and promotion of tumor } \\
\text { cell survival }\end{array}$ & oncogenic & {$[77,85]$} \\
\hline AMPK & poly-ubiquitination & degradation of AMPK & $\begin{array}{l}\text { amplification of mTORC signaling, } \\
\text { downregulation of autophagy }\end{array}$ & oncogenic & {$[105,106]$} \\
\hline FBP1 & poly-ubiquitination & degradation of FBP1 & $\begin{array}{l}\text { stimulation of the Warburg effect and } \\
\text { cancer progression }\end{array}$ & oncogenic & {$[110]$} \\
\hline $\begin{array}{l}\text { VPS34 } \\
\text { (PI3KC3) }\end{array}$ & SUMOylation & activation of VPS34 & induction of phagophore formation & oncogenic & {$[104]$} \\
\hline $\mathrm{E} 2 \mathrm{~F} 1$ & $\begin{array}{l}\text { HDAC1-mediated } \\
\text { deacetylation }\end{array}$ & inactivation of E2F1 & $\begin{array}{l}\text { suppression of E2F1-mediated apoptosis } \\
\text { after DNA damage in p53-null cells }\end{array}$ & oncogenic & {$[57,60]$} \\
\hline E2F3, E2F4 & $\begin{array}{l}\text { HDAC1-mediated } \\
\text { deacetylation }\end{array}$ & inactivation of E2F3, E2F4 & $\begin{array}{l}\text { repression of members of the E2F family } \\
\text { that are critical for cell proliferation }\end{array}$ & tumor suppressive & {$[5]$} \\
\hline MAGE-C2 & none & $\begin{array}{l}\text { interaction with MAGE-C2 increases } \\
\text { co-precipitation of TRIM } 28 \text { with ATM } \\
\text { upon genotoxic stress }\end{array}$ & enhanced repair of damaged DNA & oncogenic & {$[53]$} \\
\hline $\begin{array}{l}\text { CBF-A/ } \\
\text { FTS-1 }\end{array}$ & none & $\begin{array}{l}\text { interaction with CBF-A/FTS-1 induces } \\
\text { the expression of VIM, FSP1 and other } \\
\text { mesenchymal markers and represses } \\
\text { the expression of epithelial markers } \\
\text { (CDH1, ZO-1, etc.) }\end{array}$ & activation of EMT proteome & oncogenic & {$[71]$} \\
\hline TWIST1 & none & interaction and stabilization of TWIST1 & promoting invasion and cell migration & oncogenic & {$[26]$} \\
\hline URI-PP2A & none & $\begin{array}{l}\text { de-phosphorylation of TRIM } 28 \\
\text { (at Ser824), chromatin condensation }\end{array}$ & repression of $\mathrm{L} 1$ retroelement & tumor suppressive & {$[125]$} \\
\hline
\end{tabular}




\section{Acknowledgements}

We are extremely grateful to Prof. Julian Malicki, the Director of GPCC, Poznan, Poland, for his kind support and encouragement.

\section{Funding}

This work was supported by the Foundation for Polish Science: Welcome program grant No. 2010-3/3 to Maciej Wiznerowicz and by Greater Poland Cancer Centre intramural grants (No. 17/2016 (132) and No. 22/2016 (137)) to Patrycja Czerwińska.

\section{Availability of data and materials}

Not applicable.

\section{Authors' contributions}

PC was a major contributor in writing the manuscript. PC and SM prepared the figures. MW coordinated the manuscript preparation. All authors read and approved the final manuscript.

\section{Ethics approval and consent to participate}

Not applicable.

\section{Consent for publication}

All authors read and approved the final manuscript.

\section{Competing interests}

The authors declare that they have no competing interests.

\section{Publisher's Note}

Springer Nature remains neutral with regard to jurisdictional claims in published maps and institutional affiliations.

\begin{abstract}
Author details
${ }^{1}$ Laboratory of Gene Therapy, Department of Diagnostics and Cancer Immunology, Greater Poland Cancer Centre, 15 Garbary Street, 61-866 Poznan, Poland. ${ }^{2}$ Department of Cancer Immunology, Chair of Medical Biotechnology, Poznan University of Medical Sciences, Poznan, Poland. ${ }^{3}$ Postgraduate School of Molecular Medicine, Medical University of Warsaw, Warsaw, Poland.
\end{abstract}

Received: 31 May 2017 Accepted: 24 August 2017

\section{Published online: 29 August 2017}

\section{References}

1. Le Douarin B, Nielsen AL, Garnier JM, Ichinose H, Jeanmougin F, Losson R, et al. A possible involvement of TIF1 alpha and TIF1 Beta in the epigenetic control of transcription by nuclear receptors. EMBO J. 1996;15(23):6701-15.

2. Friedman JR, Fredericks WJ, Jensen DE, Speicher DW, Huang XP, Neilson EG, et al. KAP-1, a novel corepressor for the highly conserved KRAB repression domain. Genes Dev. 1996;10(16):2067-78.

3. Moosmann P, Georgiev O, Le Douarin B, Bourquin JP, Schaffner W Transcriptional repression by RING finger protein TIF1 beta that interacts with the KRAB repressor domain of KOX1. Nucleic Acids Res. 1996;24(24):4859-67.

4. Addison JB, Koontz C, Fugett JH, Creighton CJ, Chen D, Farrugia MK, et al. KAP1 promotes proliferation and metastatic progression of breast cancer cells. Cancer Res. 2014;75(2):344-55

5. Chen L, Chen DT, Chen T, Kurtyka C, Rawal B, Fulp WJ, et al. Tripartite motif containing 28 (Trim28) can regulate cell proliferation by bridging HDAC1/ E2F interactions. J Biol Chem. 2012;287(48):40106-18.

6. Hatakeyama S. TRIM proteins and cancer. Nat Rev Cancer. 2011;11(11):792-804.

7. Venturini L, You J, Stadler M, Galien R, Lallemand V, Koken MH, et al. TIF1gamma, a novel member of the transcriptional intermediary factor 1 family. Oncogene. 1999;18:1209-17.

8. Khetchoumian K, Teletin M, Mark M, Lerouge T, Cervino M, OuladAbdelghani M, et al. TIF1delta, a novel HP1-interacting member of the transcriptional intermediary factor 1 (TIF1) family expressed by elongating spermatids. J Biol Chem. 2004;279(46):48329-41.

9. Peng H, Begg GE, Schultz DC, Friedman JR, Jensen DE, Speicher DW, et al. Reconstitution of the KRAB-KAP-1 repressor complex: a model system for defining the molecular anatomy of RING-B box-coiled-coil domainmediated protein-protein interactions. J Mol Biol. 2000;295(5):1139-62.
10. Peng H, Begg GE, Harper SL, Friedman JR, Speicher DW, Rauscher FJ. Biochemical analysis of the Kruppel-associated box (KRAB) transcriptional repression domain: spectral, kinetic, and stoichiometric properties of the KRAB??KAP-1 complex. J Biol Chem. 2000;275(24):18000-10.

11. Peng H, Feldman I, Rauscher FJ 3rd. Hetero-oligomerization among the TIF family of RBCC/TRIM domain-containing nuclear cofactors: a potential mechanism for regulating the switch between coactivation and corepression. J Mol Biol 2002; 320(3):629-644.

12. Lechner MS, Begg GE, Speicher DW, Rauscher FJ. Molecular determinants for targeting heterochromatin protein 1-mediated gene silencing: direct chromoshadow domain-KAP-1 corepressor interaction is essential. Mol Cell Biol. 2000;20(17):6449-65.

13. Schultz DC, Friedman JR, Rauscher FJ. Targeting histone deacetylase complexes via KRAB-zinc finger proteins: the PHD and bromodomains of KAP-1 form a cooperative unit that recruits a novel isoform of the mi-2a subunit of NuRD. Genes Dev. 2001;15(4):428-43.

14. Ivanov AV, Peng H, Yurchenko V, Yap KL, Negorev DG, Schultz DC, et al. PHD domain-mediated E3 Ligase activity directs Intramolecular Sumoylation of an adjacent Bromodomain required for gene silencing. Mol Cell. 2007:28(5):823-37.

15. Cammas F, Mark M, Dolle P, Dierich A, Chambon P, Losson R. Mice lacking the transcriptional corepressor TIF1 beta are defective in early postimplantation development. Development. 2000;127(13):2955-63.

16. Lin LF, Li CF, Wang WJ, Yang WM, Wang DDH, Chang WC, et al. Loss of ZBRK1 contributes to the increase of KAP1 and promotes KAP1-mediated metastasis and invasion in cervical cancer. PLoS One. 2013;8(8):1-13.

17. Yokoe T, Toiyama Y, Okugawa Y, Tanaka K, Ohi M, Inoue Y, et al. KAP1 is associated with peritoneal carcinomatosis in gastric cancer. Ann Surg Oncol. 2010;17(3):821-8.

18. Wang YY, Li L, Zhao ZS, Wang HJ. Clinical utility of measuring expression levels of KAP1, TIMP1 and STC2 in peripheral blood of patients with gastric cancer. World J Surg Oncol. 2013;11:81.

19. Hu M, Fu X, Cui Y, Xu S, Xu Y, Dong Q, et al. Expression of KAP1 in epithelial ovarian cancer and its correlation with drug-resistance. Int J Clin Exp Med. 2015;8(10):17308-20

20. Cui Y, Yang S, Fu X, Feng J, Xu S, Ying G. High levels of KAP1 expression are associated with aggressive clinical features in ovarian cancer. Int J Mol Sci. 2014:16(1):363-77.

21. Qi Z-X, Cai J-J, Chen L-C, Yue Q, Gong Y, Yao Y, et al. TRIM28 as an independent prognostic marker plays critical roles in glioma progression. J Neuro-Oncol. 2016;126(1):19-26.

22. Jovčevska I, Zupanec N, Urlep Ž, Vranič A, Matos B, Stokin CL, et al. Differentially expressed proteins in glioblastoma multiforme identified with a nanobody-based anti-proteome approach and confirmed by OncoFinder as possible tumor-class predictive biomarker candidates. Oncotarget. 2017; [Epub ahead of print]

23. Wang Y, Jiang J, Li Q, Ma H, Xu Z, Gao Y. KAP1 is overexpressed in hepatocellular carcinoma and its clinical significance. Int J Clin Oncol. 2016:21(5):927-33.

24. Varghese S, Burness M, Xu H, Beresnev T, Pingpank J, Alexander HR. Sitespecific gene expression profiles and novel molecular prognostic factors in patients with lower gastrointestinal adenocarcinoma diffusely metastatic to liver or peritoneum. Ann Surg Oncol. 2007;14(12):3460-71.

25. Czerwińska P, Shah PK, Tomczak K, Klimczak M, Mazurek S, Sozańska B, et al. TRIM28 multi-domain protein regulates cancer stem cell population in breast tumor development. Oncotarget. 2017;8(1):863-82.

26. Wei C, Cheng J, Zhou B, Zhu L, Khan MA, He T, et al. Tripartite motif containing 28 (TRIM28) promotes breast cancer metastasis by stabilizing TWIST1 protein. Sci Rep. 2016:6:1-12.

27. Bojkowska K, Kapopoulou A, Santoni de Sio F, Aloisio F, Cassano M, Zangger $\mathrm{N}$, et al. Liver-specific ablation of KRAB associated protein 1 in mice leads to male-predominant hepatosteatosis and development of liver adenoma. Hepatology. 2012;56(4):1279-90.

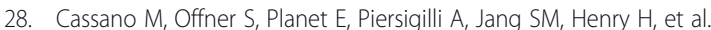
Polyphenic trait promotes liver cancer in a model of epigenetic instability. Hepatology. 2017 [E-pub ahead of print].

29. Nowick K, Hamilton AT, Zhang H, Stubbs L. Rapid sequence and expression divergence suggest selection for novel function in primate-specific KRABZNF genes. Mol Biol Evol. 2010;27(11):2606-17.

30. Huntley S, Baggott DM, Hamilton AT, Tran-Gyamfi M, Yang S, Kim J, et al. A comprehensive catalog of human KRAB-associated zinc finger genes: insights into the evolutionary history of a large family of transcriptional repressors. Genome Res. 2006;16(5):669-77. 
31. Urrutia R. KRAB-containing zinc-finger repressor proteins. Genome Biol. 2003:4(10):231.

32. Itokawa Y, Yanagawa T, Yamakawa H, Watanabe N, Koga H, Nagase T. KAP1independent transcriptional repression of SCAN-KRAB-containing zinc finger proteins. Biochem Biophys Res Commun. 2009;388(4):689-94.

33. Groner AC, Meylan S, Ciuffi A, Zangger N, Ambrosini G, Dénervaud N, et al. KRABzinc finger proteins and KAP1 can mediate long-range transcriptional repression through heterochromatin spreading. PLoS Genet. 2010;6(3):e1000869.

34. Sripathy SP, Stevens J, Schultz DC. The KAP1 corepressor functions to coordinate the assembly of de novo HP1-demarcated microenvironments of heterochromatin required for KRAB zinc finger protein-mediated transcriptional repression. Mol Cell Biol. 2006;26(22):8623-38.

35. Wiznerowicz M, Trono D. Conditional suppression of cellular genes: lentivirus vector-mediated drug-inducible RNA interference. J Virol. 2003;77(16):8957-61.

36. Szulc J, Wiznerowicz M, Sauvain M-O, Trono D, Aebischer P. A versatile tool for conditional gene expression and knockdown. Nat Methods. 2006;3(2):109-16.

37. Barde I, Laurenti E, Verp S, Groner AC, Towne C, Padrun V, et al. Regulation of episomal gene expression by KRAB/KAP1-mediated histone modifications. J Virol. 2009;83(11):5574-80.

38. lyengar S, Ivanov AV, Jin VX, Rauscher FJ, Farnham PJ. Functional analysis of KAP1 genomic recruitment. Mol Cell Biol. 2011;31(9):1833-47.

39. Murphy KE, Shylo NA, Alexander KA, Churchill AJ, Copperman C, Garcia-Garcia $\mathrm{MJ}$. The transcriptional repressive activity of KRAB zinc finger proteins does not correlate with their ability to recruit TRIM28. PLoS One. 2016;11(9):e0163555.

40. Bunch $H$, Zheng X, Burkholder A, Dillon ST, Motola S, Birrane G, et al. TRIM28 regulates RNA polymerase II promoter proximal pausing and pause release. Nat Struct Mol Biol. 2014;21(10):876-83.

41. Bunch H, Lawney BP, Burkholder A, Ma D, Zheng X, Motola S, et al. RNA polymerase II promoter-proximal pausing in mammalian long non-coding genes. Genomics. 2016;108(2):64-77.

42. lyer MK, Niknafs YS, Malik R, Singhal U, Sahu A, Hosono Y, et al. The landscape of long noncoding RNAs in the human transcriptome. Nat Genet. 2015;47(3):199-208.

43. Gutschner T, Diederichs S. The hallmarks of cancer. RNA Biol. 2012;9(6):703-19.

44. Shiloh Y. ATM and related protein kinases: safeguarding genome integrity. Nat Rev Cancer. 2003;3(3):155-68,

45. Goodarzi AA, Noon AT, Deckbar D, Ziv Y, Shiloh Y, Löbrich M, et al. ATM Signaling facilitates repair of DNA double-strand breaks associated with heterochromatin. Mol Cell. 2008;31(2):167-77.

46. Cann KL, Dellaire G. Heterochromatin and the DNA damage response: the need to relax. Biochem Cell Biol. 2011;89(1):45-60.

47. White DE, Negorev D, Peng H, Ivanov AV, Maul GG, Rauscher FJ. KAP1, a novel substrate for PIKK family members, colocalizes with numerous damage response factors at DNA lesions. Cancer Res. 2006;66(24):11594-9.

48. Ziv Y, Bielopolski D, Galanty Y, Lukas C, Taya Y, Schultz DC, et al. Chromatin relaxation in response to DNA double-strand breaks is modulated by a novel ATM- and KAP-1 dependent pathway. Nat Cell Biol. 2006;8(8):870-6.

49. Goodarzi AA, Kurka T, Jeggo PA. KAP-1 phosphorylation regulates CHD3 nucleosome remodeling during the DNA double-strand break response. Nat Struct Mol Biol. 2011;18(7):831-9.

50. Noon AT, Shibata A, Rief N, Löbrich M, Stewart GS, Jeggo P. A, et al. 53BP1dependent robust localized KAP-1 phosphorylation is essential for heterochromatic DNA double-strand break repair. Nat Cell Biol. 2010;12(2):177-84.

51. White D, Rafalska-Metcalf IU, Ivanov AV, Corsinotti A, Peng H, Lee S-C, et al. The ATM substrate KAP1 controls DNA repair in heterochromatin: regulation by HP1 proteins and serine 473/824 Phosphorylation. Mol Cancer Res. 2012; 10(3):401-14.

52. Murray JM, Stiff T, Jeggo PA. DNA double-strand break repair within heterochromatic regions. Biochem Soc Trans. 2012;40(1):173-8.

53. Bhatia N, Xiao TZ, Rosenthal KA, Siddiqui IA, Thiyagarajan S, Smart B, et al. MAGEC2 promotes growth and tumorigenicity of melanoma cells, phosphorylation of KAP1, and DNA damage repair. J Invest Dermatol. 2013;133(3):759-67.

54. Chang C-W, Chou H-Y, Lin Y-S, Huang K-H, Chang C-J, Hsu T-C, et al. Phosphorylation at Ser473 regulates heterochromatin protein 1 binding and corepressor function of TIF1 beta/KAP1. BMC Mol Biol. 2008;9:61.

55. Blasius M, Forment JV, Thakkar N, Wagner SA, Choudhary C, Jackson SP. A phospho-proteomic screen identifies substrates of the checkpoint kinase Chk1. Genome Biol. 2011;12(8):R78.

56. Lee D-H, Goodarzi A. A, Adelmant GO, pan Y, Jeggo P a, Marto J a, et al. Phosphoproteomic analysis reveals that PP4 dephosphorylates KAP-1 impacting the DNA damage response. EMBO J. 2012;31(10):2403-15.
57. Hu C, Zhang S, Gao X, Gao X, Xu X, Lv Y, et al. Roles of Kruppel-associated box (KRAB)-associated co-repressor KAP1 ser-473 Phosphorylation in DNA damage response. J Biol Chem. 2012;287(23):18937-52.

58. Bolderson E, Savage Kl, Mahen R, Pisupati V, Graham ME, Richard DJ, et al. Kruppel-associated box (KRAB)-associated co-repressor (KAP-1) ser-473 phosphorylation regulates heterochromatin protein 1 beta (HP1-beta) mobilization and DNA repair in heterochromatin. J Biol Chem. 2012;287(33):28122-31.

59. Magni M, Ruscica V, Restelli M, Fontanella E, Buscemi G, Zannini L. CCAR2/ DBC1 is required for Chk2-dependent KAP1 phosphorylation and repair of DNA damage. Oncotarget. 2015;6(19):17817-31.

60. Wang C, Rauscher FJ, Cress WD, Chen J. Regulation of E2F1 function by the nuclear corepressor KAP1. J Biol Chem. 2007;282(41):29902-9.

61. Kalluri R, Weinberg RA. The basics of epithelial-mesenchymal transition. J Clin Invest. 2009;119(6):1420-8.

62. Scheel C, Weinberg RA. Cancer stem cells and epithelial-mesenchymal transition: concepts and molecular links. Semin Cancer Biol. 2012;22(5-6):396-403.

63. Lamouille S, Xu J, Derynck R. Molecular mechanisms of epithelialmesenchymal transition. Nat Rev Mol Cell Biol. 2014;15(3):178-96.

64. Yao D, Dai C, Peng S. Mechanism of the Mesenchymal-epithelial transition and its relationship with metastatic tumor formation. Mol Cancer Res. 2011:9(12):1608-20.

65. Serrano-Gomez SJ, Maziveyi M, Alahari SK. Regulation of epithelialmesenchymal transition through epigenetic and post-translational modifications. Mol Cancer. 2016;15(1):1-14.

66. Heerboth S, Housman G, Leary M, Longacre M, Byler S, Lapinska K, et al. EMT and tumor metastasis. Clin Transl Med. 2015;26(4):6.

67. Radisky ES, Radisky DC. Matrix metalloproteinase-induced epithelialMesenchymal transition in breast cancer. J Mammary Gland Biol Neoplasia. 2010;15(2):201-12.

68. Iden S, Collard JG. Crosstalk between small GTPases and polarity proteins in cell polarization. Nat Rev Mol Cell Biol. 2008;9(11):846-59.

69. Ansieau S, Collin G, Hill L. EMT or EMT-promoting transcription factors, where to focus the light? Front Oncol. 2014;4:353.

70. Morel A-P, Lièvre M, Thomas C, Hinkal G, Ansieau S, Puisieux A. Generation of breast cancer stem cells through epithelial-mesenchymal transition. PLoS One. 2008;3(8):e2888.

71. Venkov CD, Link AJ, Jennings JL, Plieth D, Inoue T, Nagai K, et al. A proximal activator of transcription in epithelial-mesenchymal transition. J Clin Invest. 2007;117(2):482-91.

72. Okada H, Danoff TM, Fischer A, Lopez-Guisa JM, Strutz F, Neilson EG Identification of a novel cis-acting element for fibroblast-specific transcription of the FSP1 gene. Am J Phys. 1998;275(2 Pt 2):F306-14.

73. Yu C, Zhan L, Jiang J, Pan Y, Zhang H, Li X, et al. KAP-1 is overexpressed and correlates with increased metastatic ability and tumorigenicity in pancreatic cancer. Med Oncol. 2014;31(7):25.

74. Chen L, Munõz-Antonia T, Cress WD. Trim28 contributes to EMT via regulation of E-cadherin and $\mathrm{N}$-cadherin in lung cancer cell lines. PLoS One. 2014;9(7):e101040

75. Mani SA, Guo W, Liao M-J, Eaton EN, Ayyanan A, Zhou AY, et al. The epithelial-mesenchymal transition generates cells with properties of stem cells. Cell. 2008;133(4):704-15.

76. Polyak K, Weinberg RA. Transitions between epithelial and mesenchymal states: acquisition of malignant and stem cell traits. Nat Rev Cancer. 2009;9(4):265-73.

77. Okamoto K, Kitabayashi I, Taya Y. KAP1 dictates p53 response induced by chemotherapeutic agents via Mdm2 interaction. Biochem Biophys Res Commun. 2006;351(1):216-22.

78. Sigal A, Rotter V. Oncogenic mutations of the p53 tumor suppressor: the demons of the Guardian of the genome. Cancer Res. 2000;60(24):6788-93.

79. Brown CJ, Lain S, Verma CS, Fersht AR, Lane DP. Awakening guardian angels: drugging the p53 pathway. Nat Rev Cancer. 2009;9(12):862-73.

80. Strano S, Dell'Orso S, Di Agostino S, Fontemaggi G, Sacchi A, Blandino G. Mutant p53: an oncogenic transcription factor. Oncogene. 2007;26(15):2212-9.

81. Haupt Y, Maya R, Kazaz A, Oren M. Mdm2 promotes the rapid degradation of p53. Nature. 1997;387(6630):296-9.

82. Kubbutat $\mathrm{MHG}$, Jones $\mathrm{SN}$, Vousden $\mathrm{KH}$. Regulation of $\mathrm{p} 53$ stability by Mdm2. Nature. 1997;387(6630):299-303.

83. Vogelstein B, Lane D, Levine AJ. Surfing the p53 network. Nature. 2000; 408(6810):307-10.

84. Manfredi JJ. The Mdm2-p53 relationship evolves: Mdm2 swings both ways as an oncogene and a tumor suppressor. Genes Dev. 2010;24(15):1580-9. 
85. Wang C, Ivanov A, Chen L, Fredericks WJ, Seto E, Rauscher FJ, et al. MDM2 interaction with nuclear corepressor KAP1 contributes to p53 inactivation. EMBO J. 2005;24(18):3279-90.

86. Doyle JM, Gao J, Wang J, Yang M, Potts PR. MAGE-RING protein complexes comprise a family of E3 Ubiquitin Ligases. Mol Cell. 2010;39(6):963-74.

87. Thomson JA, Itskovitz-Eldor J, Shapiro SS, Waknitz MA, Swiergiel JJ, Marshall VS, et al. Embryonic stem cell lines derived from human blastocysts. Science. 1998;282(5391):1145-7.

88. Young RA. Control of embryonic stem cell state. Cell. 2011;144(6):940-54

89. Hu G, Kim J, Xu Q, Leng Y, Orkin SH, Elledge SJ. A genome-wide RNA screen identifies a new transcriptional module required for self-renewal. Genes Dev. 2009;23(7):837-48.

90. Seki Y, Kurisaki A, Watanabe-Susaki K, Nakajima Y, Nakanishi M, Arai Y, et al. TIF1 beta regulates the pluripotency of embryonic stem cells in a phosphorylationdependent manner. Proc Natl Acad Sci U S A. 2010;107(24):10926-31.

91. Jin VX, O'Geen H, lyengar S, Green R, Farnham PJ. Identification of an OCT4 and SRY regulatory module using integrated computational and experimental genomics approaches. Genome Res. 2007;17(6):807-17.

92. Yang BX, Farran CA, Guo HC, Yu T, Fang HT, Wang HF, et al. Systematic identification of factors for provirus silencing in embryonic stem cells. Cell. 2015:163(1):230-45.

93. Cheng B, Ren Z, Kerppola TK. KAP1 represses differentiation-inducible genes in embryonic stem cells through cooperative binding with PRC1 and Derepresses Pluripotency-associated genes. Mol Cell Biol. 2014;34(11):2075-91.

94. Catherine Miles D, Alexandra de Vries N, Gisler S, Lieftink C, Akhtar W, Gogola E, et al. TRIM28 is an epigenetic barrier to induced Pluripotent stem cell reprogramming. Stem Cells. 2017;35(1):147-57.

95. Klimczak M, Czerwińska P, Mazurek S, Sozańska B, Biecek P, Mackiewicz A, et al. TRIM28 epigenetic corepressor is indispensable for stable induced pluripotent stem cell formation. Stem Cell Res. 2017:23:163-72.

96. Li J, Xi Y, Li W, McCarthy RL, Stratton SA, Zou W, et al. TRIM28 interacts with $\mathrm{EZH} 2$ and SWI/SNF to activate genes that promote mammosphere formation. Oncogene. 2017 [E-pub ahead of print]

97. Czerwinska P, Kaminska B. Regulation of breast cancer stem cell features. Contemp Oncol (Pozn). 2015;19(1A):A7-A15.

98. Mathew R, Karantza-Wadsworth V, White E. Role of autophagy in cancer. Nat Rev Cancer. 2007;7(12):961-7.

99. Rosenfeldt MT, Ryan KM. The multiple roles of autophagy in cancer Carcinogenesis. 2011;32(7):955-63.

100. Cufí S, Vazquez-Martin A, Oliveras-Ferraros C, Martin-Castillo B, Vellon L, Menendez JA. Autophagy positively regulates the CD44(+) CD24(-/low) breast cancer stem-like phenotype. Cell Cycle. 2011;10(22):3871-85.

101. Gong C, Bauvy C, Tonelli G, Yue W, Deloménie C, Nicolas V, et al. Beclin 1 and autophagy are required for the tumorigenicity of breast cancer stemlike/progenitor cells. Oncogene. 2013;32(18):2261-72. 2272e.1-11

102. Maycotte $P$, Jones KL, Goodall ML, Thorburn J, Thorburn A. Autophagy supports breast cancer stem cell maintenance by regulating IL6 secretion. Mol Cancer Res. 2015;13(4):651-8

103. Yang M-C, Wang H-C, Hou Y-C, Tung H-L, Chiu T-J, Shan Y-S. Blockade of autophagy reduces pancreatic cancer stem cell activity and potentiates the tumoricidal effect of gemcitabine. Mol Cancer. 2015;14(1):1-17.

104. Yang Y, Fiskus W, Yong B, Atadja P, Takahashi Y, Pandita TK, et al. Acetylated hsp70 and KAP1-mediated Vps34 SUMOylation is required for autophagosome creation in autophagy. Proc Natl Acad Sci U S A. 2013; 110(17):6841-6.

105. Pineda $C T$, Ramanathan S, Fon Tacer $K$, Weon $\lrcorner$, Potts MB, Ou YH, et al. Degradation of AMPK by a cancer-specific ubiquitin ligase. Cell. 2015;160(4):715-28.

106. Pineda CT, Potts PR. Oncogenic MAGEA-TRIM28 ubiquitin ligase downregulates autophagy by ubiquitinating and degrading AMPK in cancer. Autophagy. 2015;11(5):844-6.

107. Tooze SA, Yoshimori T. The origin of the autophagosomal membrane. Nat Cell Biol. 2010;12(9):831-5.

108. Cicchini M, Karantza V, Xia B. Molecular pathways: Autophagy in cancer-a matter of timing and context. Clin Cancer Res. 2015;21(3):498-504

109. Barde I, Rauwel B, Marin-Florez RM, Corsinotti A, Laurenti E, Verp S, et al. A KRAB/KAP1-miRNA Cascade regulates Erythropoiesis through stage-specific control of Mitophagy. Science. 2013;340(6130):350-3.

110. Jin $X$, Pan $Y$, Wang $L$, Zhang $L$, Ravichandran $R$, Potts $P R$, et al. MAGETRIM28 complex promotes the Warburg effect and hepatocellular carcinoma progression by targeting FBP1 for degradation. Oncogene. 2017;6(4):e312.
111. Lee E, Iskow R, Yang L, Gokcumen O, Haseley P, Luquette LJ 3rd, et al. Landscape of somatic retrotransposition in human cancers. Science. 2012; 337(6097):967-71.

112. Lander ES, Linton LM, Birren B, Nusbaum C, Zody MC, Baldwin J, et al. Initial sequencing and analysis of the human genome. Nature. 2001;409(6822):860-921.

113. Kazazian HHJ. Mobile elements: drivers of genome evolution. Science. 2004; 303(5664):1626-32.

114. Rowe HM, Jakobsson J, Mesnard D, Rougemont J, Reynard S, Aktas T, et al. KAP1 controls endogenous retroviruses in embryonic stem cells. Nature. 2010;463(7278):237-40.

115. Rowe HM, Kapopoulou A, Corsinotti A, Fasching L, Macfarlan TS, Tarabay Y, et al. TRIM28 repression of retrotransposon-based enhancers is necessary to preserve transcriptional dynamics in embryonic stem cells. Genome Res. 2013;23(3):452-61

116. Castro-Diaz N, Friedli M, Trono D. Drawing a fine line on endogenous retroelement activity. Mob Genet Elements. 2015;5(1):1-6.

117. Wolf D, Goff SP. TRIM28 mediates primer binding site-targeted silencing of Murine Leukemia virus in embryonic cells. Cell. 2007;131(1):46-57.

118. Matsui T, Leung D, Miyashita H, Maksakova IA, Miyachi $H$, Kimura $H$, et al. Proviral silencing in embryonic stem cells requires the histone methyltransferase ESET. Nature. 2010;464(7290):927-31.

119. Van Meter M, Kashyap M, Rezazadeh S, Geneva AJ, Morello TD, Seluanov A, et al. SIRT6 represses LINE1 retrotransposons by ribosylating KAP1 but this repression fails with stress and age. Nat Commun. 2014:5:5011.

120. Castro-Diaz N, Ecco G, Coluccio A, Kapopoulou A, Yazdanpanah B, Friedli M, et al. Evolutionally dynamic L1 regulation in embryonic stem cells. Genes Dev. 2014;28(13):1397-409.

121. Tan X, Xu X, Elkenani M, Smorag L, Zechner U, Nolte J, et al. Zfp819, a novel KRAB-zinc finger protein, interacts with KAP1 and functions in genomic integrity maintenance of mouse embryonic stem cells. Stem Cell Res. 2013; 11(3):1045-59.

122. Turelli P, Castro-Diaz N, Marzetta F, Kapopoulou A, Raclot C, Duc J, et al. Interplay of TRIM28 and DNA methylation in controlling human endogenous retroelements. Genome Res. 2014;24(8):1260-70.

123. Estécio MRH, Gharibyan V, Shen L, Ibrahim AEK, Doshi K, He R, et al. LINEHypomethylation in cancer is highly variable and inversely correlated with microsatellite instability. Cardoso MC, editor. PLoS One. 2007; 2(5):e399.

124. Iskow RC, McCabe MT, Mills RE, Torene S, Pittard WS, Neuwald AF, et al. Natural mutagenesis of human genomes by endogenous retrotransposons. Cell. 2010;141(7):1253-61.

125. Mita P, Savas JN, Briggs EM, Ha S, Gnanakkan V, Yates JR III, et al. URI regulates KAP1 Phosphorylation and transcriptional repression via PP2A Phosphatase in prostate cancer cells. J Biol Chem. 2016;291(49):25516-28.

126. Mita P, Savas JN, Ha S, Djouder N, Yates JR III, Logan SK. Analysis of URI nuclear interaction with RPB5 and components of the R2TP/Prefoldin-like complex. PLoS One. 2013:8(5):e63879.

127. Yang B, O'Herrin SM, Wu J, Reagan-Shaw S, Ma Y, Bhat KMR, et al. MAGE-A, mMage- $b$, and MAGE-C proteins form complexes with KAP1 and suppress p53-dependent apoptosis in MAGE-positive cell lines. Cancer Res. 2007; 67(20):9954-62.

128. Tian C, Xing G, Xie P, Lu K, Nie J, Wang J, et al. KRAB-type zinc-finger protein Apak specifically regulates p53-dependent apoptosis. Nat Cell Biol. 2009;11(5):580-91.

129. Li X, Lee YK, Jeng JC, Yen Y, Schultz DC, Shih HM, et al. Role for KAP1 serine 824 phosphorylation and sumoylation/desumoylation switch in regulating KAP1-mediated transcriptional repression. J Biol Chem. 2007;282(50):36177-89.

130. Jen J, Wang YC. Zinc finger proteins in cancer progression. J Biomed Sci. 2016;23(1):53. 